\title{
Aspectos epidemiológicos, clínicos, hematológicos e anatomopatológicos da leucemia eritroide aguda (LMA M6) em gatos ${ }^{1}$
}

\author{
Camila Tochetto ${ }^{2}$, Tatiana M. Souza ${ }^{3}$, Claudio S.L. Barros ${ }^{3}$ e Rafael A. Fighera ${ }^{3 *}$
}

\begin{abstract}
Tochetto C., Souza T.M., Barros C.S.L. \& Fighera R.A. 2011. [Epidemiological, clinical, hematological, and pathological aspects of acute erythroid leukemia (LMA M6) in cats.] Aspectos epidemiológicos, clínicos, hematológicos e anatomopatológicos da leucemia eritroide aguda (LMA M6) em gatos. Pesquisa Veterinária Brasileira 31(7):610-619. Departamento de Patologia, Universidade Federal de Santa Maria, Av. Roraima 1000, Santa Maria, RS 97105-900, Brazil.E-mail: anemiaveterinaria@yahoo.com.br

The epidemiological, clinical, hematological, and pathological aspects of acute erythroid leukemia (LMA M6) were studied in 10 cats that died from this condition. The results obtained in the present study differ from those previously described in the literature regarding the following aspects: 1) The disease occurred as a bimodal model related to the age of affected cats, in which $50 \%$ were $1-3$-years-old and $50 \%$ were 10 years-old or above; 2 ) almost all affected cats $(87.5 \%)$ displayed polychromasia, possible resulting from extramedullar erythropoiesis; 3 ) in all cases there were multiple foci of hematopoietic cells, mainly erythropoietic, in multiple organs including spleen (85.7\%), lymph nodes (71.4\%), liver (57.1\%), and kidney (28.6\%); 4) in some cases $(28.6 \%)$ these foci could be observed on gross examination as metastasis, but they always histologically differ from bone marrow in regard to the proportion of erythroid precursors involved; 5) at least in one case a continuum patologicum occurred with the condition evolving to another form of LMA (LMA M4), a phenomenon coined as "lineage infidelity". This paper discuss these differences and stresses the fundamental criteria to establish a definitive diagnosis of this condition, which is the most import form of leukemia in cats from our region.

INDEX TERMS: Diseases of cats, hematology, hematopathology, acute erythroid leukemia, erythroleukemia, erythremic myelosis.
\end{abstract}

RESUMO.- Os aspectos epidemiológicos, clínicos, hematológicos e anatomopatológicos da leucemia eritroide aguda (LMA M6) foram estudados em 10 gatos que morreram em consequência dessa condição. Os resultados obtidos diferem daqueles previamente descritos na literatura nos seguintes aspectos: 1) a doença ocorreu na forma de um modelo bimodal relacionado à idade dos gatos afetados, em que $50 \%$ tinham 1-3 anos de idade e $50 \%$ tinham 10 anos de idade ou mais; 2) quase todos os gatos afetados $(87,5 \%)$ demonstravam policromasia, possivelmente decorrente de eritropoese extramedular; 3 ) em todos os casos havia múltiplos focos de células hematopoéticas, principalmente eritropoeticas, em múltiplos órgãos, que

\footnotetext{
${ }^{1}$ Recebido em 28 de março de 2011.

Aceito para publicação em 14 de abril de 2011.

${ }^{2}$ Programa de Pós-Graduação em Medicina Veterinária, área de concentração em Patologia Veterinária, Centro de Ciências Rurais (CCR), Universidade Federal de Santa Maria (UFSM), Camobi, Santa Maria, RS 97105-900, Brasil.

${ }^{3}$ Departamento de Patologia, UFSM, Av. Roraima 1000, Santa Maria, RS 97105-900. *Autorparacorrespondência:anemaveterinaria@yahoo.com.br
}

incluíam baço (85,7\%), linfonodos $(71,4 \%)$, fígado $(57,1 \%)$ e rim $(28,6 \%) ; 4)$ em alguns casos $(28,6 \%)$ esses focos podiam ser vistos macroscopicamente, na forma de metástases, mas sempre diferiam histologicamente da medula óssea quanto à proporção dos precursores eritroides envolvidos; 5) em pelo menos um caso ocorreu um continuum patologicum até outra forma de LMA (LMA M4), um fenômeno denominado "infidelidade de linhagem". Esse artigo discute essas diferenças e reforça os critérios fundamentais para se estabelecer o diagnóstico definitivo dessa que é a forma mais importante de leucemia em gatos na nossa região.

TERMOS DE INDEXAÇÃO: Doenças de gatos, hematologia, hematopatologia, leucemia eritroide aguda, eritroleucemia, mielose eritrêmica.

\section{INTRODUÇÃO}

Leucemia eritroide aguda é uma forma de apresentação de neoplasia do sistema hematopoético em que há envolvimento de células imaturas do compartimento eritroide (Valli et al. 2002). 
Segundo o Grupo de Estudos Franco-Americano-Britânico (Grupo FAB) (Bennett et al 1976) e a Organização Mundial de Saúde (OMS) (Jaffe et al. 2001), que se baseia no Clinical Advisory Committee Meeting, ocorrido em Airlie House, Virginia, em Novembro de 1997 (Harris et al. 2000), leucemia eritroide aguda é classificada como uma forma de leucemia mieloide aguda (LMA M6) e subdividida em duas formas de apresentação clinicopatológicas: LMA M6A, mais frequentemente descrita em humanos (Valli 2007a), e LMA M6B, muito mais comumente relatada em animais, principalmente em camundongos (Ney \& D'Andrea 2000, Moreau-Gachelin 2006) e gatos (Jain et al. 1991, Valli 2007a,b), e raramente em cães (Anderson \& Johnson 1962, Groulade \& Guillon 1967, Liu \& Carb 1968, Tolle et al. 1977), bovinos (Watanabe et al. 1998), chimpanzés (McClure et al. 1974) e ratos (Groulade \& Guillon 1967, Bird \& Huggins 1971). A primeira, também denominada de eritroleucemia, consiste em um neoplasma bilinhagem, que envolve mieloblastos e eritroblastos (Bennett et al 1976, Jain et al. 1991, Harris et al. 2000). A segunda, também chamada mielose eritrêmica (Bennett et al. 1976, Valli 2007a,b), leucemia eritroide pura (Harris et al. 2000, Jaffe et al. 2001), eritroleucemia com predominância eritroide (Jaffe et al. 2001), LMA M6Er (Jain et al 1991) e eritremia aguda (Jarret \& MacKey 1974), é um distúrbio que afeta unicamente a linhagem eritroide (Bennett et al. 1976, Jain et al 1991). Durante anos, em relação à LMA M6B, em medicina veterinária, tem-se dado preferência à denominação mielose eritrêmica (Jain 1986, Moulton \& Harvey 1990, Jain 1993, Jacobs et al. 2002, Valli et al. 2002, Valli 2007a,b, Fighera \& Graça 2010), já em medicina humana, as expressões leucemia eritroide pura e eritroleucemia com predominância eritroide são atualmente bem mais usuais (Jaffe et al. 2001, Bain 2003).

Embora leucemia eritroide aguda seja considerada como a mais comum apresentação da leucemia mieloide aguda em gatos (Valli 2007a), há poucos casos descritos na literatura científica. Tais relatos referem-se sempre a apenas um (Zawidzka et al. 1964, Saar 1968, Ward et al. 1969, Hurvitz 1970, Schalm 1975a,b, Harvey et al. 1978, Maede et al. 1979, Falconer et al. 1980, Maede \& Murata 1980, Engelman et al. 1986, Comazzi et al. 2000) ou dois casos (Watson et al. 1974, Shimada et al. 1995). Assim, o objetivo deste trabalho é apresentar os achados epidemiológicos, clínicos, hematológicos e anatomopatológicos vistos em 10 gatos com LMA M6, a fim de auxiliar clínicos e patologistas veterinários no diagnóstico dessa doença que acomete gatos em nossa região.

\section{MATERIAL E MÉTODOS}

Os casos incluídos neste trabalho ocorreram entre 2001 e 2010, no Município de Santa Maria, localizado na Mesorregião do Centro Ocidental Rio-Grandense, popularmente conhecida como Região Central. Foram considerados apenas casos espontâneos e fatais da doença $(n=10)$.

Os achados epidemiológicos e os dados clínicos foram fornecidos pelos veterinários responsáveis por cada caso quando da requisição da necropsia ou da biópsia aspirativa de medula óssea. Hemogramas foram realizados em todos os gatos, através de contadores semi-automatizados ou automatizados de células. Oito dos 10 gatos tiveram seus esfregaços sanguíneos reavaliados por um dos autores (R.A.F.). Nesses oito casos, os esfregaços sanguíneos foram confeccionados com sangue coletado 1-12 dias antes da morte do gato e corados por panótico rápido para avaliação da morfologia das células sanguíneas.

Avaliação citológica da medula óssea, incluindo contagem diferencial dos precursores hematopoéticos (mielograma), foi realizada em todos os gatos e a interpretação dos resultados foi baseada no clássico trabalho de Schalm (1972). Em três desses gatos a avaliação foi realizada 1-10 dias antes da morte, nos outros sete, os esfregaços foram confeccionados a partir de tecido medular coletado à necropsia. Dos 10 gatos afetados, sete foram necropsiados. Vários fragmentos de órgãos foram colhidos à necropsia, fixados em formol a $10 \%$, processados rotineiramente para histologia e corados pela hematoxilina e eosina (HE). 0 encéfalo foi fixado inteiro e fragmentos foram processados da mesma maneira para histologia. A avaliação histológica da medula óssea desses casos foi completada pela avaliação citológica.

0 método de inclusão dos casos neste estudo foi o diagnóstico definitivo de LMA M6 através de critérios da OMS para classificação dos tumores hematopoéticos, publicados em 2002 pelo Instituto de Patologia das Forças Armadas (AFIP) (Valli et al. 2002), e que tem como base os parâmetros estabelecidos em 1991 pelo Grupo de Estudos da Leucemia Animal (ALSG) da Sociedade Americana de Patologia Clínica Veterinária (Jain et al. 1991). Esses parâmetros, por sua vez, estão embasados no sistema de classificação do Grupo FAB, publicado em 1976 (Bennett et al. 1976) e revisto em 1988 (MIC Cooperative Study Group 1988) e 1998 (Bain 1998). Assim, para ser diagnosticada LMA M6 foi necessário que no mielograma os gatos apresentassem: 1) no mínimo $50 \%$ das células nucleadas da medula óssea (CNMO) pertencentes ao compartimento eritroide; e 2) pelo menos $20 \%-30 \%$ do total de células nucleadas não eritroides da medula óssea (CNNEMO) correspondentes a mieloblastos; ou 3) pelo menos $20 \%-30 \%$ do total de CNMO correspondentes a rubriblastos. A subclassificação da LMA M6 em A ou B foi realizada com base nessa mesma classificação, em que o diagnóstico da LMA M6A se aplica quando no mínimo 20\%-30\% do total de CNNEMO corresponde a mieloblastos e o diagnóstico de LMA M6B é confirmado quando pelo menos 20\%-30\% do total de CNMO correspondem a rubriblastos.

\section{RESULTADOS}

\section{Epidemiologia}

Dos 10 gatos com LMA M6, cinco (50\%) eram machos e cinco (50\%) eram fêmeas. A idade dos gatos afetados variou de um a 14 anos; cinco (50\%) eram adultos jovens, com até três anos de idade (1-3 anos) e cinco (50\%) eram idosos, com 10 anos de idade ou mais (10-14 anos). Apenas três dos 10 gatos $(30 \%)$ demonstravam algum padrão racial (dois siameses e um persa), porém nenhum deles apresentava critérios necessários para ser considerado puro. Os demais eram gatos sem raça definida. Dos 10 gatos afetados, quatro (40\%) morreram espontaneamente e seis $(60 \%)$ foram submetidos à eutanásia.

\section{Sinais clínicos}

De modo geral, os gatos aqui descritos $(n=10)$ demonstraram uma doença caracterizada invariavelmente por apatia, anorexia ou inapetência e emagrecimento ou caquexia, com evolução clínica de duas semanas a dois meses. Anemia, evidenciada clinicamente por graus variados de palidez das mucosas oral (Fig.1) e conjuntival, foi vista em nove dos 10 gatos afetados (90\%). Esplenomegalia foi observada através da palpação abdominal em metade dos gatos (5/10 [50\%]). Linfadenomegalia superficial generalizada foi observada em al- 


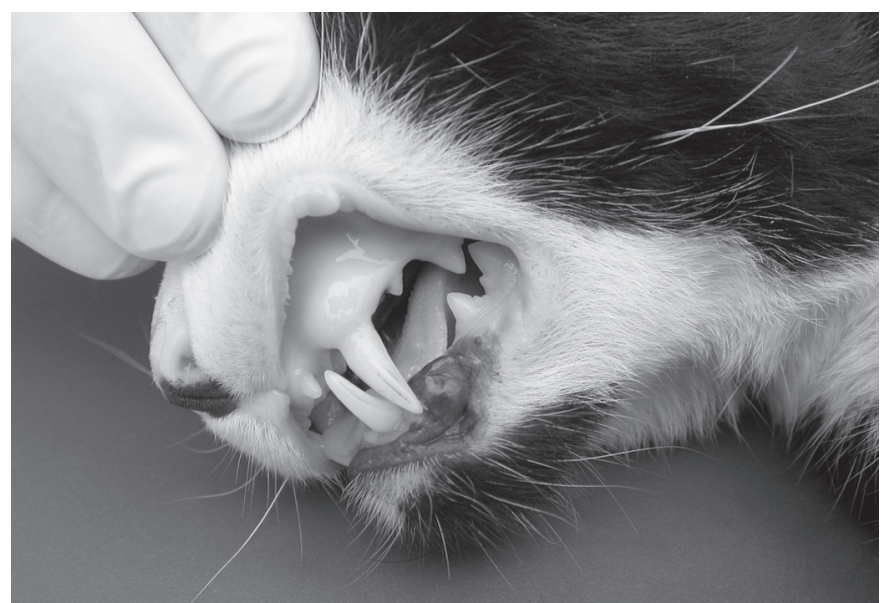

Fig.1. Mucosa oral. Marcada palidez das mucosas, um aspecto clínico muito prevalente nessa forma de leucemia.

guns gatos $(3 / 10$ [30\%]). Hemorragia foi vista em poucos gatos $(2 / 10[20 \%])$, era leve e afetava apenas a mucosa oral, na forma de petéquias ou sufusões. Nesses dois casos havia histórico de diarreia com sangue digerido (melena). Alguns poucos gatos $(2 / 10$ [20\%] apresentaram ascite e dispneia decorrente de derrame pleural. Pelo menos um desses gatos (1/10 [10\%]) demonstrou edema subcutâneo nas porções ventrais do tronco. Outros sinais clínicos foram observados com baixa frequência (1/10 [10\%]) e incluíram: salivação, disfagia, protrusão da língua, convulsão e poliúria/polidipsia.

Dos 10 casos aqui descritos, em nenhum havia suspeita clínica da doença. Os diagnósticos diferenciais nesses casos incluíam principalmente micoplasmose hemotrópica (previamente hemobartonelose), linfoma e peritonite infecciosa felina, mas também uma gama de outras doenças não relacionadas.

\section{Hematologia}

No hemograma $(n=10)$ da maioria dos casos $(9 / 10$ [90\%]) pôde-se observar anemia de intensidade variável com hematócritos entre 7\% (Fig.2) e 17\%. A contagem de eritró-

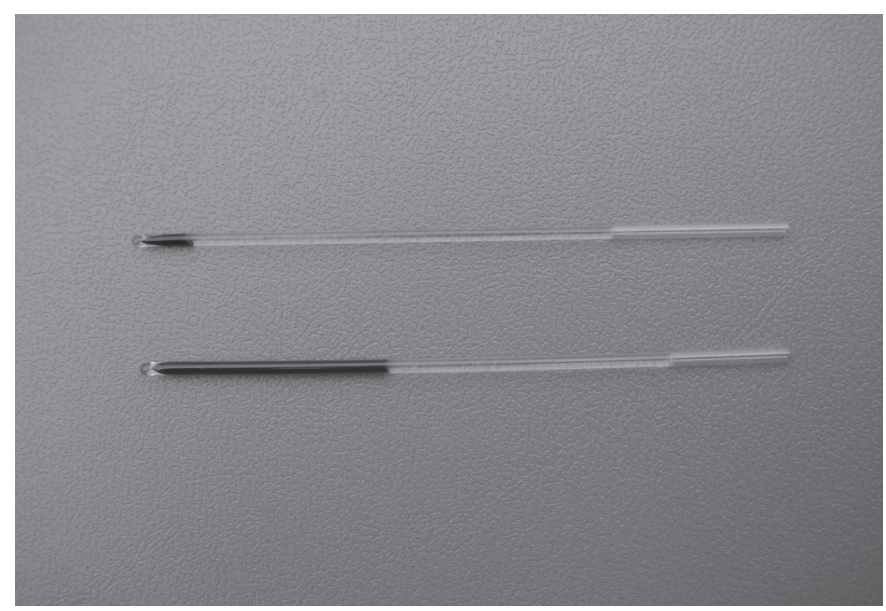

Fig.2. Capilares de micro-hematócrito. 0 capilar superior demonstra baixa relação do éritron em relação ao plasma (hematócrito de $7 \%$ ), um aspecto muito diferente do capilar inferior, referente a um gato controle (hematócrito de $42 \%$ ). Observe que o plasma é totalmente incolor. citos e os níveis de hemoglobina oscilaram de 0,9-2,7 milhões/ $\mathrm{mm}^{3}$ de sangue e de $2,0-5,7 \mathrm{~g} / \mathrm{dl}$ de sangue, respectivamente. Em seis casos (6/9 [66,7\%]) a anemia era macrocítica normocrômica, com volume corpuscular médio (VCM) entre 62,9 e 77,8 fentolitros e concentração de hemoglobina corpuscular média (CHCM) entre $31,1 \%$ e $33,5 \%$. Nos outros três casos (3/9 [33,3\%]), a anemia era macrocítica hipocrômica, com VCM entre 70,1 e 81,2 fentolitros e CHCM entre 28,6\% e $29,8 \%$. No único caso em que não havia anemia $(1 / 10$ [10\%]), o hematócrito, a contagem de eritrócitos e os níveis de hemoglobina eram próximos do limite mínimo dos valores de referência (26\%, 5,3 milhões $/ \mathrm{mm}^{3}$ de sangue e 9,1 g/ dl de sangue, respectivamente).

A contagem de leucócitos esteve alterada em vários casos (6/10 [60\%]). Em quase todos esses casos (4/6 [66,7\%]) ocorreu leucocitose que oscilou entre 22.300 e 41.600 leucócitos/ $\mathrm{mm}^{3}$ de sangue, entretanto, em alguns deles $(2 / 6$ [33,3\%]) ocorreu leucopenia, que oscilou entre 2.200 e 4.800 leucócitos $/ \mathrm{mm}^{3}$ de sangue. A leucocitose foi sempre em decorrência do aumento moderado ou acentuado na quantidade de neutrófilos. Em todos os casos em que houve neutrofilia, o aumento na quantidade de neutrófilos era, em parte, decorrente de um incremento na quantidade de precursores, basicamente bastonetes. A leucopenia foi sempre decorrente da diminuição moderada ou acentuada na quantidade de neutrófilos. Em um dos gatos afetados (Gato 4) (1/10 [10\%]), os hemogramas realizados três e dois dias antes da eutanásia, cerca de dois meses após o diagnóstico inicial, apresentou contagens de leucócitos que variavam entre 173.800 e 182.400 leucócitos $/ \mathrm{mm}^{3}$ de sangue. Trombocitopenia foi observada em alguns gatos (4/10 [40\%]); nesses casos, as contagens oscilaram entre 38.000 e 54.000 plaquetas $/ \mathrm{mm}^{3}$ de sangue. Em apenas dois casos (20\%) o plasma era levemente ictérico.

Os achados hematológicos vistos na totalidade dos esfregaços sanguíneos examinados $(\mathrm{n}=8)$ caracterizavam-se por intensa anisocitose (8/8 [100\%]), marcada normoblastemia (8/8 [100\%]) e variáveis graus (leve a acentuado) de policromasia (7/8 [87,5\%]) (Fig.3) e presença de corpúsculos de Howell-Jolly (2/8 [25\%]). 0 total de eritroblastos observados em todos os casos variou de 20 a 240/100 leucócitos, o que correspondeu a 1.800 a 24.100 eritroblastos $/ \mathrm{mm}^{3}$ de sangue. A maior parte dos eritroblastos correspondia a metarrubrícitos (82\%-98\%), mas, em todos os casos, uma proporção menor de rubrícitos (2\%-18\%) fazia parte da população eritroide nucleada circulante. Um achado característico, observado em todos os casos (8/8 [100\%]), porém com intensidade variável, foi a presença de eritroblastos com características megaloblastoides decorrente de maturação nucleocitoplasmática assincrônica (Fig.4). Em pelo menos um caso $(1 / 8[12,5 \%])$ havia grande quantidade de bastonetes, metamielócitos e mielócitos em associação com a normoblastemia, manifestando uma típica reação leucoeritroblástica. Nesse caso, muitos dos neutrófilos maduros demonstravam inclusões azul-pálidas ou azul-acinzentadas, com 0,5 a 2,0 $\mathrm{mm}$ de diâmetro, localizadas próximas à periferia da célula (corpúsculos de Döhle).

Em um dos gatos (Gato 4), aquele que demonstrou marcada leucocitose previamente a eutanásia, a normoblastemia havia diminuído marcadamente e havia acentuada 

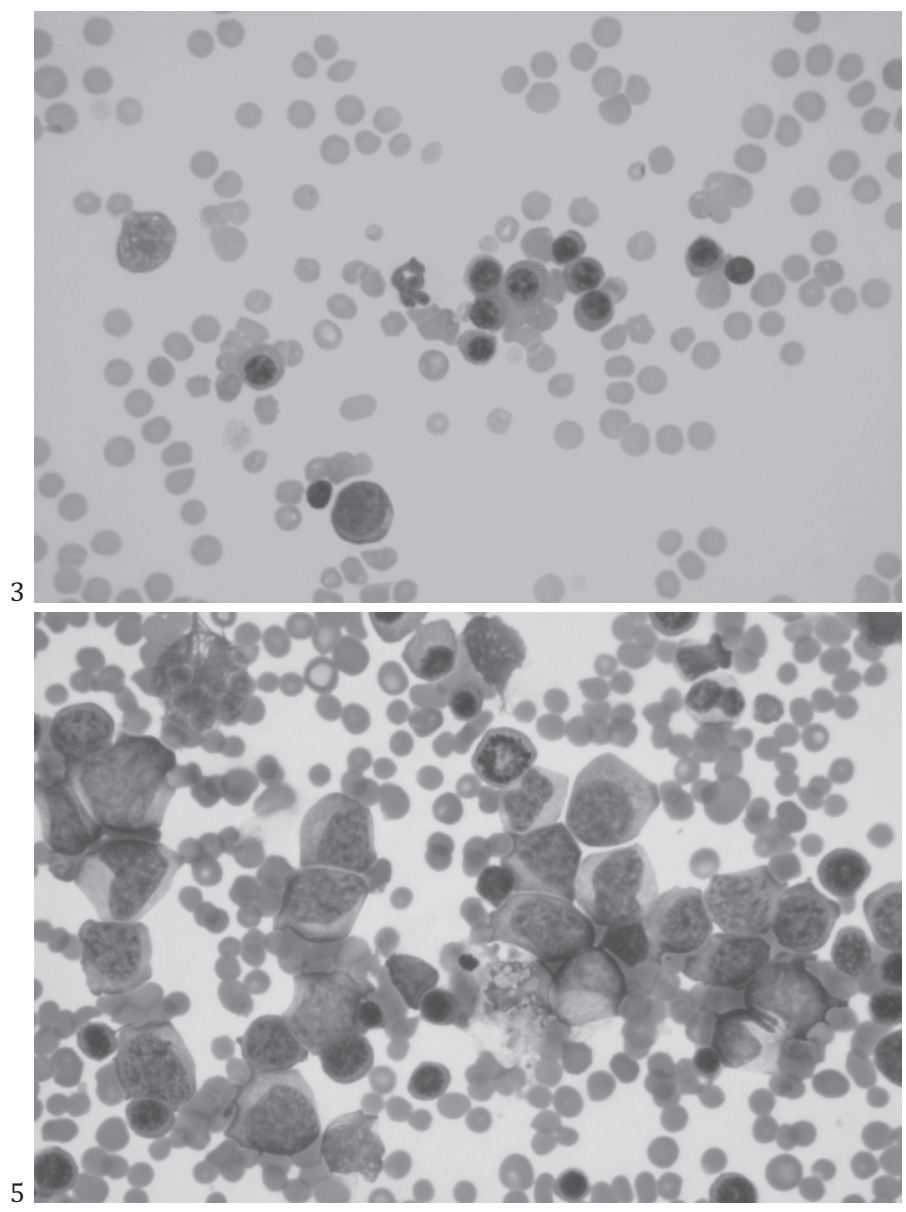

quantidade de bastonetes, metamielócitos, mielócitos, promielócitos, mieloblastos, promonócitos e monoblastos circulantes, o que permitiu a suspeita clínica de leucemia mielomonocítica aguda (LMA M4).

No mielograma de todos os casos (10/10 [100\%]) havia marcada inversão da relação mieloide:eritroide caracterizada por valores que oscilaram entre 0,05 e 0,4. Do total de células nucleadas da medula óssea (CNMO), pelo menos 30\% correspondiam a blastos, mieloblastos ou rubriblastos. Em nove dos 10 casos (90\%) avaliados citologicamente, o total de rubriblastos variou entre $22 \%$ e $56 \%$ e a percentagem de mieloblastos foi inferior a $6 \%$. Esses nove casos foram interpretados como LMA M6B (Fig.5). Em um dos 10 casos (10\%), o total de rubriblastos foi $24 \%$ e o total de mieloblastos de $38 \%$, totalizando $62 \%$ de blastos do total de CNMO. Esse caso foi interpretado como LMA M6A. Em um dos 10 gatos (Gato 4), o único em que a avaliação foi repetida previamente antes da morte, houve marcada mudança no mielograma. Nesse caso, a percentagem de rubriblastos havia diminuído de $44 \%$ para $5 \%$ e o número de mieloblastos e monoblastos somados havia aumentado de $2 \%$ para $35 \%$. Esse caso foi interpretado como uma evolução de LMA M6B para LMA M4.

Dentre as alterações morfológicas observadas nas avaliações citológicas da medula óssea destacou-se principalmente a binucleação ou trinucleação de metarrubrícitos e rubrícitos, a picnose nuclear de rubrícitos, as mitoses anômalas (mitose de metarrubrícito), a abundante quantidade de citoplasma basofílico (rubrícitos megaloblastoides), caracterizando

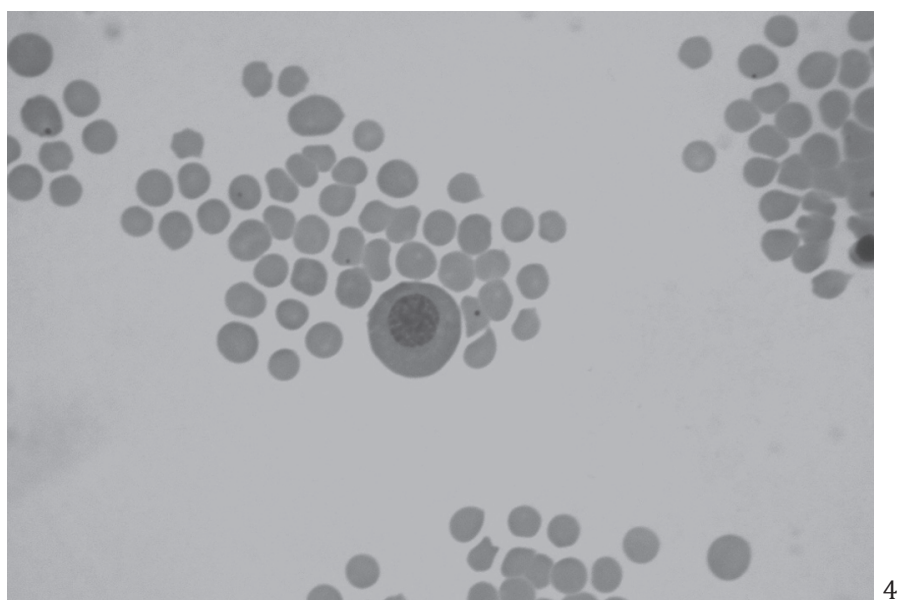

Fig.3. Esfregaço sanguíneo. Leve anisocitose e policromasia e marcada normoblastemia (nove metarrubrícitos, duas hematogôneas e um rubriblasto). Panótico, obj.40x.

Fig.4. Esfregaço sanguíneo. Rubrícito megaloblastoide. Observe a marcada anisocitose e policromasia e a presença de corpúsculos de Howell-Jolly. Panótico, obj.40x.

Fig.5. Esfregaço medular. Grande quantidade de blastos caracterizados por núcleo excêntrico formado por cromatina frouxa com nucléolos pouco evidentes e citoplasma escasso e intensamente basofílico (morfologia típica de rubriblasto). Nesse caso, o mielograma demonstrou $56 \%$ de rubriblastos e apenas $2 \%$ de mieloblastos, o que permitiu o diagnóstico de LMA M6B. Panótico, obj.40x.

maturação nucleocitoplasmática assincrônica, e a redução da fusão nuclear dos megacariócitos.

\section{Achados de necropsia}

Na necropsia $(n=7)$, todos os gatos apresentavam um conjunto de lesões que caracterizava tipicamente o estado anêmico. As mucosas externamente visíveis (oral, ocular e genital) eram marcadamente pálidas e o sangue era pouco viscoso ("sangue aquoso") (Fig.6). A maior parte dos gatos (5/7 [71,4\%]) demonstrava estado corporal ruim, eram magros e tinham pelagem baça. Pelo menos dois gatos eram caquéticos (2/7 [28,6\%]).

Em aproximadamente a metade dos casos $(3 / 7[42,8 \%])$, todos os linfonodos, superficiais e profundos, estavam moderada a acentuadamente aumentados de volume e intensamente vermelhos (Fig.7). Ao corte eram macios e deixavam fluir pequena quantidade de líquido. À superfície de corte eram homogêneos, vermelhos, úmidos e brilhantes.

Quatro dos sete gatos $(57,1 \%)$ tinham baços aumentados de volume (entre duas e 10 vezes o tamanho normal) e com bordos arredondados. Dois desses gatos $(28,6 \%)$ tinham o baço com superfície natural lisa (Fig.8), já nos outros dois (28,6\%), a superfície natural do baço era marcadamente irregular (Fig.9). Essa irregularidade era dada pela retração tecidual. Tais áreas de retração eram marcadamente brancas e contrastavam com o restante do órgão, que era vermelho e entremeado por finas listras branco-amareladas. Esse padrão irregular de apresentação foi interpretado como cicatrização pós-necrótica. Ao corte, em nenhum dos casos fluía sangue, mas a polpa vermelha protruia levemente sobre a cápsula e a superfície de corte tinha "aspecto carnoso". 

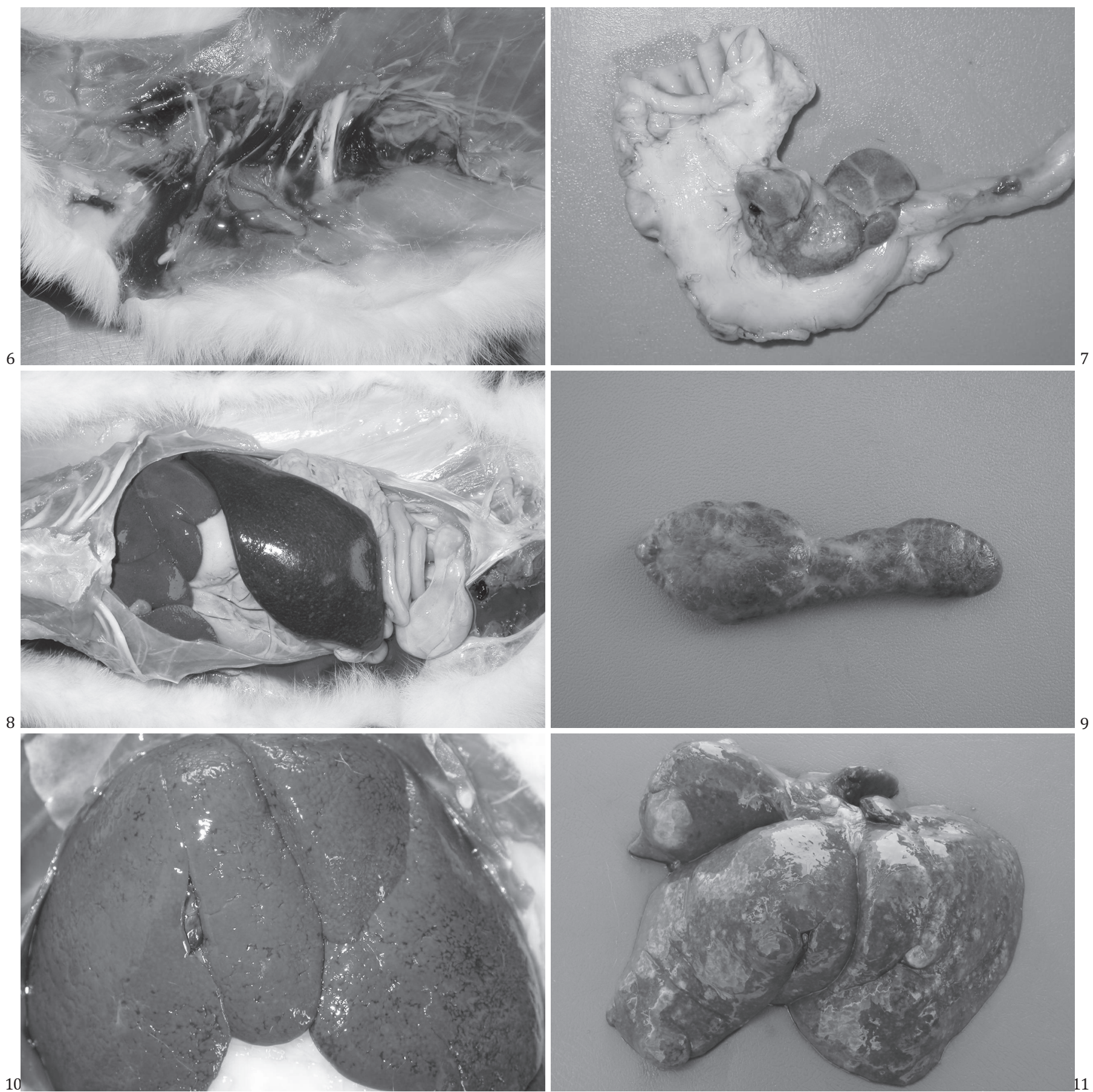

Fig.6. Região cérvico-torácica lateral direita. Quando a musculatura dessa região era cortada, o sangue que fluía dos vasos tinha aspecto marcadamente aquoso.

Fig.8. Baço. Esplenomegalia acentuada. Nessa forma de apresentação, o baço tinha superfície lisa. Note que os bordos do fígado ultrapassam marcadamente os limites do arco costal.

Fig.10. Fígado. Descoloração difusa. 0 fígado é marrom-bronzeado e tem a superfície natural entrecortada por múltiplas áreas vermelhas com padrão serpiginoso.

O fígado apresentava alterações macroscópicas na grande maioria dos casos (5/7 [71,4\%]); essas alterações incluíam, em ordem decrescente de frequência: mudanças na cor do órgão (5/7 [71,4\%]), que assumia uma tonalidade marrom-clara $(2 / 7[28,6 \%])$ a marrom-bronzeada $(3 / 7$

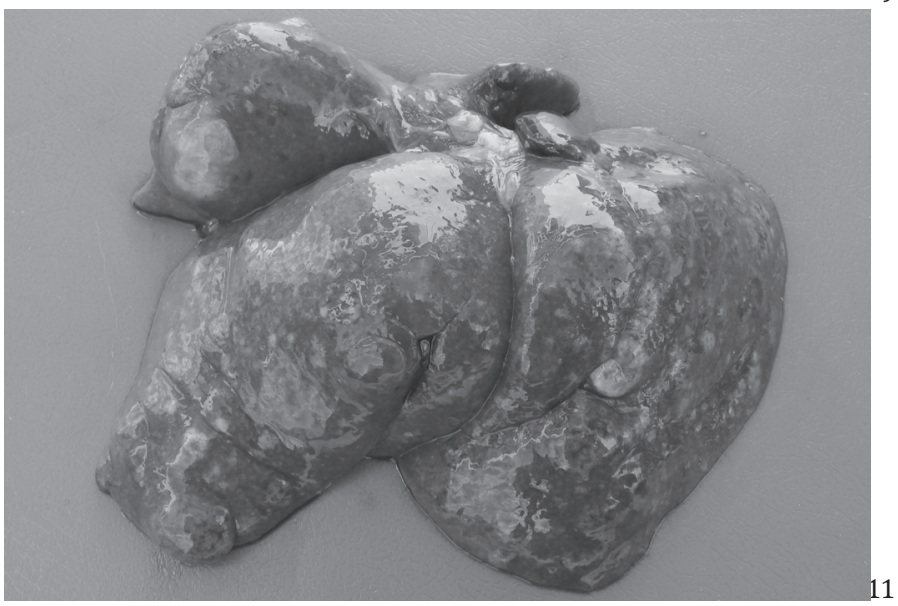

Fig.7. Estômago e linfonodos gástricos. Acentuado aumentado de volume e pigmentação vermelha, um aspecto típico de obliteração nodal pelo tecido eritroide.

Fig.9. Baço. Superfície natural irregular, caracterizada por áreas brancas e branco-amareladas de retração tecidual.

Fig.11. Fígado. Múltiplos nódulos brancos e branco-avermelhados distribuídos aleatoriamente em todos os lobos, em um típico padrão de metastatização difusa.

[42,9\%]); aumento de volume (2/7 [28,6\%]); acentuação do padrão lobular, vistas tanto na superfície natural quanto na de corte $(2 / 6$ [28,6\%]); múltiplas áreas vermelhas com padrão serpiginoso que se distribuíam em várias direções na superfície capsular (Fig.10) e de corte (1/7 [14,3\%]); múlti- 


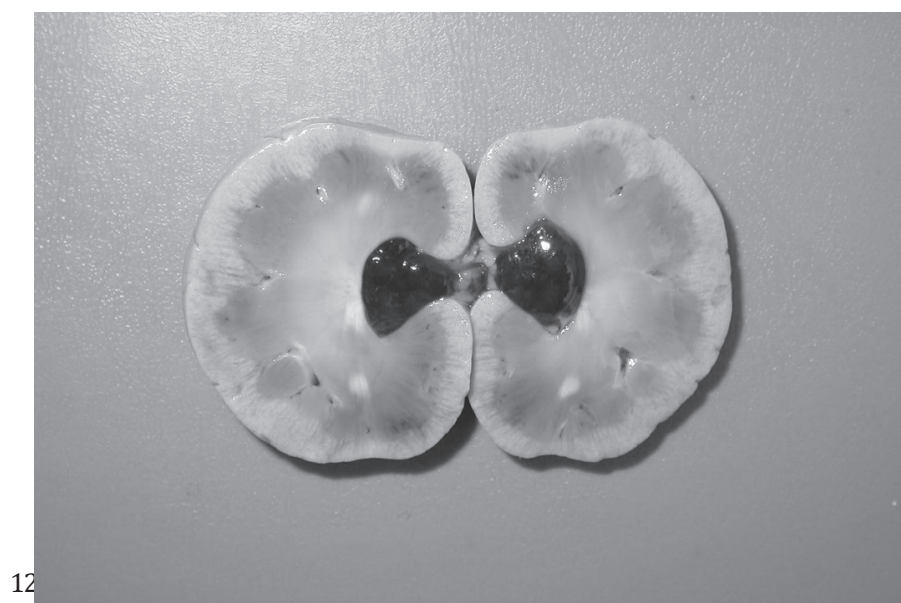

Fig.12. Rim, superfície de corte. Massa vermelha e brilhante que distende e obstrui completamente a pelve renal.

Fig.13. Medula óssea, fêmur. A porção diafisária do osso está totalmente preenchida por medula óssea vermelha, o padrão típico dessa forma de leucemia, porém macroscopicamente indistinguível de hiperplasia eritroide.

Fig.14. Intestino delgado, jejuno. Conteúdo intestinal vermelho-escuro em decorrência da hemorragia acentuada da mucosa.

plos nódulos brancos ou branco-avermelhados distribuídos aleatoriamente em todos os lobos (Fig.11), como um padrão de metastatização difusa $(1 / 7$ [14,73\%]).

Macroscopicamente, com exceção dos linfonodos, baço e fígado, apenas nos rins $(2 / 7$ [28,6\%]) foram vistas áreas brancas, vermelhas ou branco-avermelhadas, que pudessem sugerir metástases. Em um desses casos, a pelve do rim direito estava distendida e totalmente obstruída por uma massa vermelha e brilhante com 1,5 x 0,8 x 0,7 cm (Fig.12). Em todos os casos, a medula óssea era acentuadamente vermelha e preenchia todo o canal medular dos fêmures (Fig.13) e úmeros.

Apenas dois dos sete gatos $(28,6 \%)$ apresentaram hemorragia à necropsia. Tais hemorragias ocorriam como petéquias e sufusões e afetavam a mucosa oral, o tecido subcutâneo, a mucosa do trato gastrintestinal e a superfície epicárdica. Nos casos em que afetavam o intestino delgado, a hemorragia tingia o conteúdo intestinal de vermelho-escuro (Fig.14).

Outros achados de necropsia, não diretamente associados à leucemia e que foram considerados incidentais, incluíam: hidrotórax, ascite, edema subcutâneo, edema palpebral, colângio-hepatite linfocitária, cirrose biliar, "rim em estágio terminal", hipoplasia renal unilateral, doença periodontal e gengivite/faucite plasmocitária. Esses achados foram ocasionais $(1 / 7[14,3 \%])$ e ocorreram em casos distintos ou em um mesmo caso.

\section{Achados histopatológicos}

Na histopatologia ( $\mathrm{n}=7)$, em todos os casos, a medula óssea demonstrava marcada proliferação hematopoética caracterizada pelo desaparecimento completo ou quase completo do tecido adiposo. Não havia diferença entre a quantidade de tecido adiposo visto em diferentes locais do fêmur e úmero. Essa proliferação distribuía-se na forma de um manto de células sem estroma perceptível. A maior parte das células era de blastos com 12-15 $\mu$ m de diâmetro, caracterizados por terem

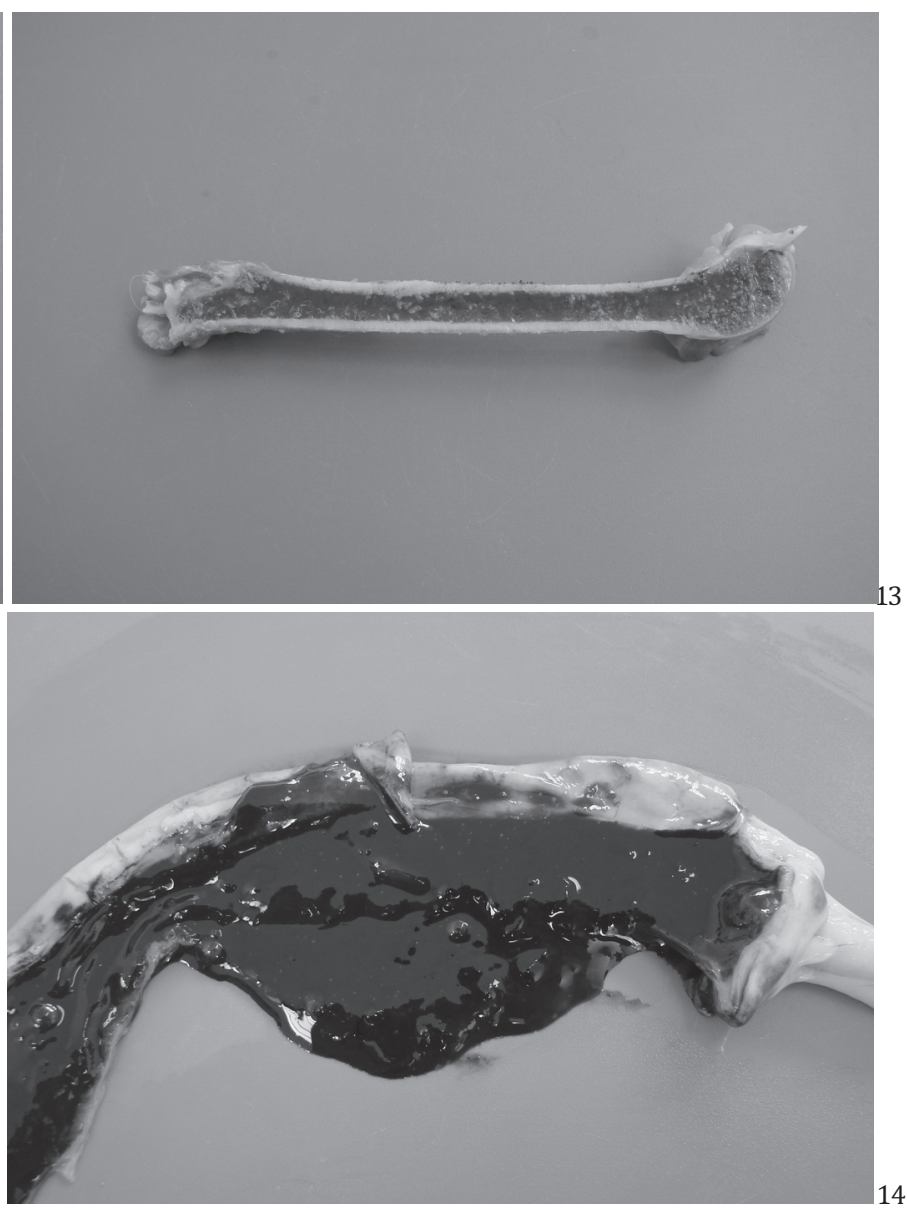

citoplasma abundante e eosinofílico. 0 núcleo desses blastos era central ou levemente excêntrico, formado por cromatina frouxa e com um nucléolo único, conspícuo e variavelmente eosinofílico (Fig.15). Blastos binucleados e mitoses eram frequentes. A quantidade de precursores eritroides menos imaturos era variável, mas constituída principalmente por rubrícitos. Metarrubrícitos constituíam a menor parcela do compartimento eritroide e alguns deles tinham citoplasma abundante e eosinofílico (anomalia megaloblastoide) (Fig.16). Pré-rubrícitos eram vistos apenas em alguns campos de maior aumento. Seis desses sete casos $(85,7 \%)$ foram interpretados como LMA M6B, pois havia marcada diminuição do compartimento mieloide, sobretudo da linhagem granulocítica (hipoplasia granulocítica mielotísica). Em um dos sete casos (14,3\%), além das alterações eritroides previamente descritas, havia muitas células com núcleo clivado ou reniforme, o que dava à medula óssea um aspecto bem menos homogêneo do que os outros seis casos (Fig.17). Essas células foram interpretadas como pertencendo à linhagem granulocítica e o caso foi interpretado como LMA M6A. Em todos os seis casos havia marcado aumento na quantidade de precursores da linhagem megacariocítica. Essa proliferação era constituída principalmente de megacarioblastos, a maior parte deles com anomalias nucleares, principalmente déficit de fusão nuclear (displasia megacariocítica) (Fig.18). Menor quantidade de megacariócitos e alguns pré-megacariócitos podiam também ser vistos.

No baço (6/7 [85,7\%]), nos linfonodos (5/7 [71,4\%]), no fígado $(4 / 7[57,1 \%])$ e no rim $(2 / 7[28,6 \%])$, havia múlti- 


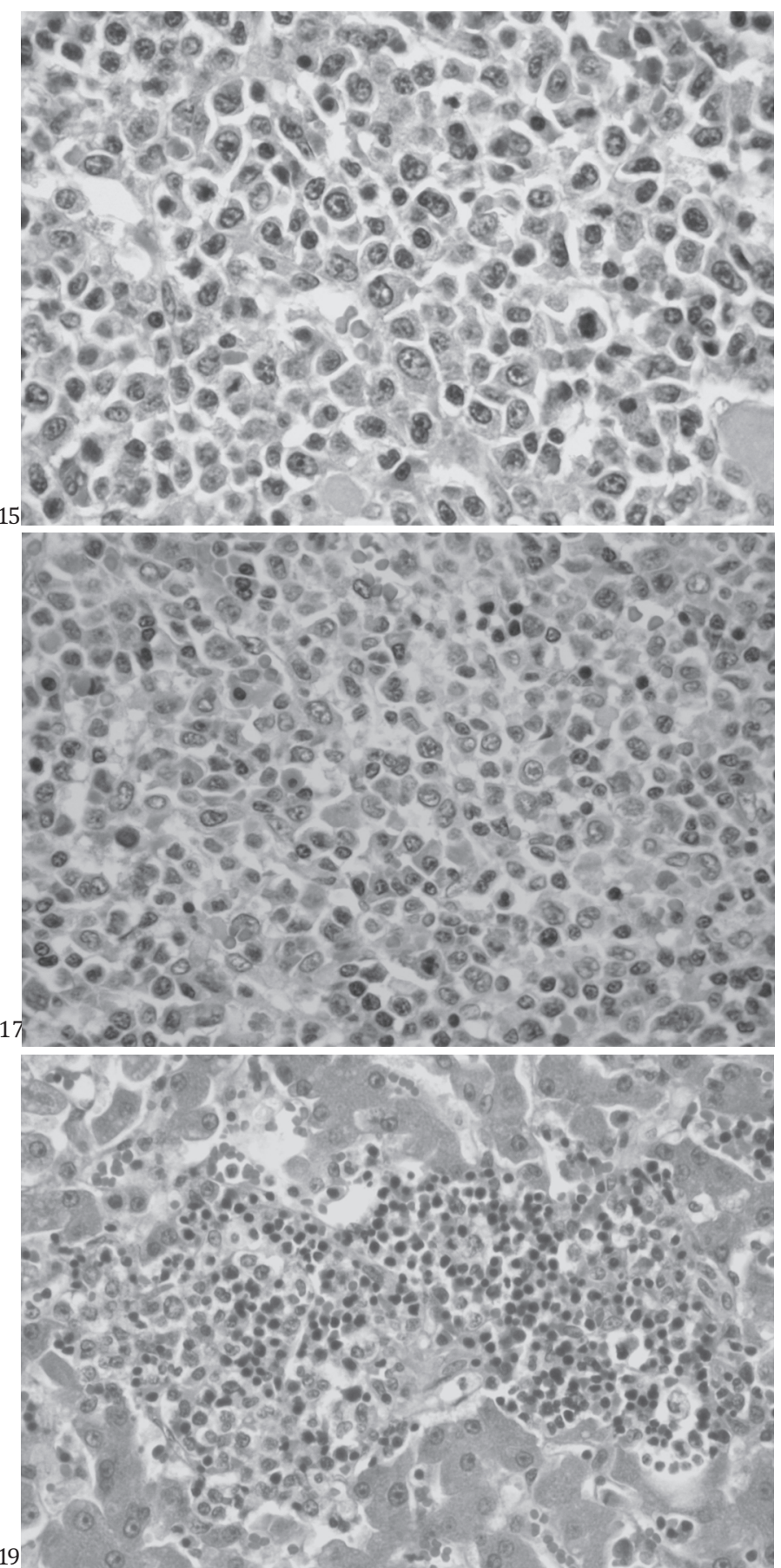

Fig.15. Medula óssea. Proliferação hematopoética na forma de manto de células sem estroma perceptível. Abundante quantidade de blastos caracterizados pelo nucléolo eosinofílico conspícuo. 0 núcleo excêntrico e o citoplasma abundante permitem sua classificação como rubriblastos e o diagnóstico de LMA M6B. HE, obj.20x.

Fig.17. Medula óssea. Nesse caso, além da proliferação blástica, semelhante à vista na Fig.15, há várias células com núcleo clivado ou reniforme. Essa diferenciação mieloide permite o diagnóstico de LMA M6A. HE, obj.20x.

Fig.19. Fígado. Espaço-porta obliterado por precursores hematopoéticos em fase de maturação. Há predomínio de precursores eritroides, basicamente metarrubrícitos e rubrícitos, e menor quantidade de precursores mieloides, principalmente mielócitos e metamielócitos. HE, obj.20x.
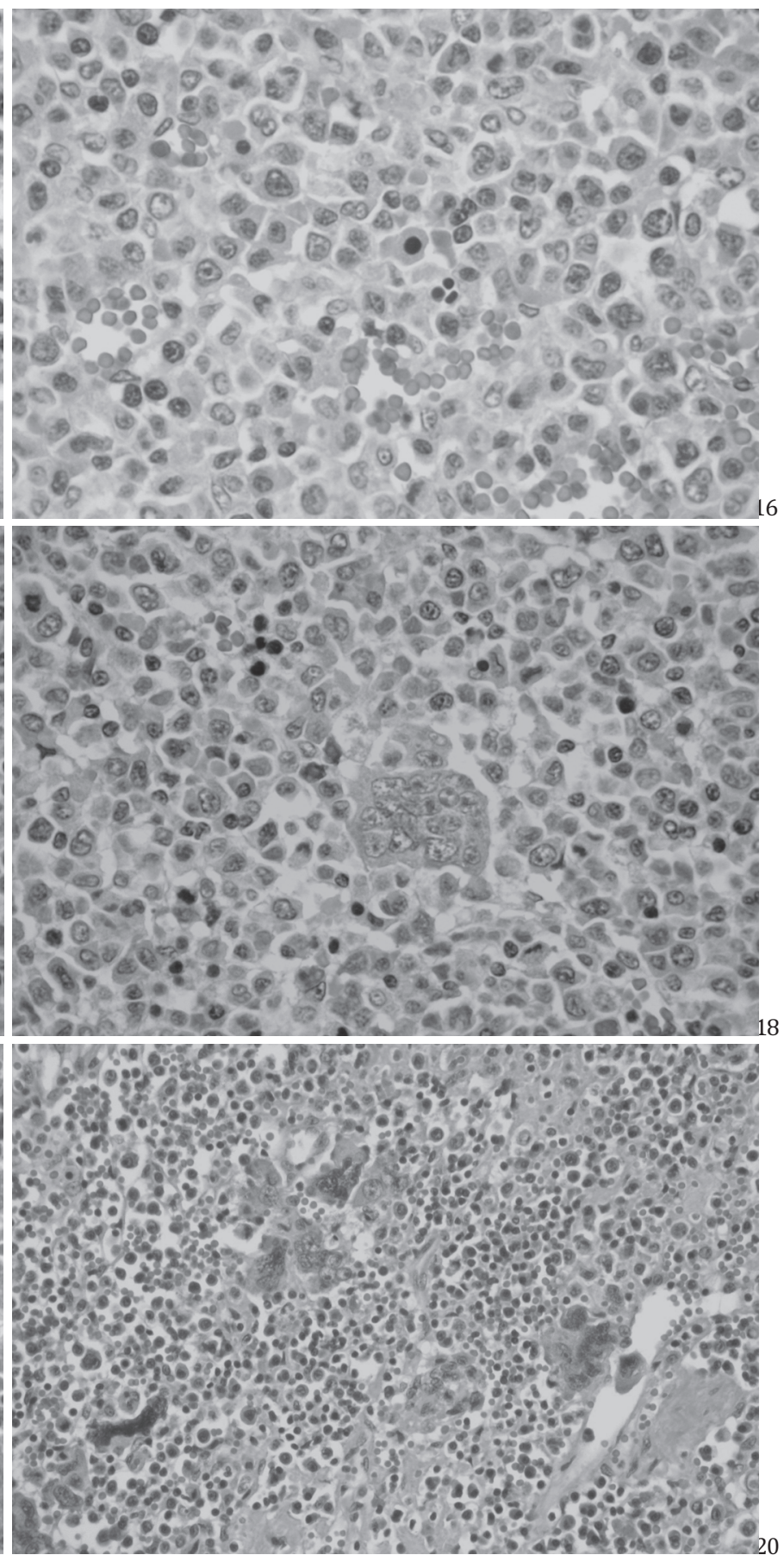

Fig.16. Medula óssea. No centro do campo há um eritroblasto com a típica anomalia megaloblastoide decorrente de maturação nucleocitoplasmática assincrônica, o mecanismo patogênico principal para o desenvolvimento da anemia nesses casos. HE, obj.20x.

Fig.18. Medula óssea. Megacarioblasto multinucleado em decorrência de déficit na fusão nuclear (displasia megacariocítica). HE, obj.20x.

Fig.20. Baço, polpa vermelha. Grande quantidade de precursores hematopoéticos, principalmente da linhagem megacariocítica. A maior parte são megacarioblastos displásicos. Há leve fibrose dos cordões de Billroth. HE, obj.20x. 
plos focos de células hematopoéticas. Esses focos eram distribuídos aleatoriamente na polpa vermelha, no paracórtex, ao redor dos espaços-porta e na medular interna, respectivamente. No baço, agrupamentos de células eritroides eram vistos frequentemente $(4 / 7[57,1 \%])$ na parede de vasos trabeculares, um padrão denominado "colonização subendotelial". No fígado, em dois casos (2/7 [28,6\%]) havia grande quantidade de precursores eritroides obstruindo e distendendo os sinusoides. No fígado e no rim, em pelo menos dois casos (2/7 [28,6\%]), essas células formavam grandes aglomerados, que podiam ser vistos macroscopicamente na forma de nódulos. Todas essas áreas, independentemente do tamanho, eram constituídas basicamente por precursores eritroides pequenos, com até 10-12 $\mu \mathrm{m}$ de diâmetro. Essas células foram interpretadas como metarrubrícitos e rubrícitos (Fig.19). Em todos os casos, quantidades variáveis de megacarioblastos e megacariócitos, mas apenas poucos pré-megacariócitos, eram observados (Fig.20). Em pelo menos um caso, havia também grande quantidade de precursores da linhagem granulocítica, principalmente mielócitos, metamielócitos e bastonetes.

No fígado, em todos os casos avaliados, havia moderada a grande quantidade de pigmento castanho-dourado e granular em células de Kupffer e em hepatócitos. Esse pigmento era fortemente positivo na marcação pelo Azul da Prússia e foi interpretado como hemossiderina. Muitos macrófagos do baço e linfonodos também tinham citoplasma repleto desse mesmo pigmento. Na maioria dos fígados (5/7 [71,4\%]) havia necrose com padrão zonal do tipo paracentral, um reflexo da hipóxia resultante da anemia. Em alguns baços (2/7 [28,6\%]) havia fibrose, de intensidade variável de acordo com a localização. Em alguns cortes podia-se notar que afetava os cordões de Billroth, já em outros era difusa na polpa vermelha.

\section{DISCUSSÃO}

Os achados epidemiológicos, clínicos, hematológicos e anatomopatológicos observados nesses 10 casos de LMA M6 são semelhantes aos descritos na literatura (Jain 1986, Moulton \& Harvey 1990, Jain 1993, Jacobs et al. 2002, Valli et al. 2002, Valli 2007a,b, Fighera \& Graça 2010), entretanto, algumas diferenças foram observadas e alguns novos achados foram encontrados. Tais aspectos norteiam essa discussão.

0 aspecto epidemiológico mais interessante observado nos casos aqui descritos foi a ocorrência da LMA M6 na forma de um modelo bimodal relacionado à idade dos gatos afetados. A metade dos gatos doentes tinha 1-3 anos de idade, e a outra metade tinha 10 anos de idade ou mais. Além disso, notase que nenhum caso ocorreu no intervalo entre três e 10 anos de idade, um resultado totalmente diferente do que é descrito na literatura norte-americana, que coloca essa doença como afetando gatos entre três e 7-8 anos de idade (Valli 2007a). Esse achado nos permite a interpretação de que, em nossa região, essa forma de leucemia afeta basicamente dois grupos etários bem distintos, adultos jovens e idosos, um aspecto epidemiológico idêntico ao descrito para o linfoma em gatos. Nos casos de linfoma, a explicação está na infecção pelo vírus da leucemia felina (FeLV). Assim, em relação ao linfoma felino, há uma premissa que se tornou bastante conhecida e utilizada pelos clínicos de pequenos animais: "gatos com linfoma com menos de sete anos de idade, provavelmente o linfoma é induzido pelo FeLV, gatos com linfoma com mais de sete anos, provavelmente o linfoma não é causado pelo FeLV" (Couto 1992). Entretanto, como desconhecemos se algum desses gatos havia sido infectado pelo FeLV, não podemos saber se o comportamento bimodal referente à idade dos gatos afetados pela LMA M6 é semelhante ao do linfoma. Porém, é bastante plausível aventar essa hipótese, que merece ser posteriormente avaliada, a fim de ser confirmada ou refutada, pois LMA é reconhecidamente associada ao FeLV desde a década de 1960 (Kawakami et al. 1967) e LMA M6 desde a década de 1970 (Oshiro et al. 1971).

Em relação à hematologia, um resultado bastante contrastante foi a ocorrência de policromasia em sete dos oito casos $(87,5 \%)$ em que esse parâmetro pôde ser avaliado. Segundo alguns autores (Jain 1986, Jain 1993, Jacobs et al. 2002, Valli et al. 2002, Valli 2007a,b), uma das características hematológicas mais marcantes da LMA M6 é a ocorrência de anisocitose sem policromasia, o que reflete uma falha no compartimento de maturação eritroide (Morrison 2001). Entretanto, relatos isolados de casos de LMA M6 com policromasia podem ser encontrados (Harvey et al. 1978). Embora a medula óssea desses mesmos casos tenha sido avaliada citologicamente e histologicamente e demonstrado uma diminuição muito grande do compartimento de maturação eritroide em decorrência da proliferação desordenada das células do compartimento de multiplicação, acreditamos que os policromatófilos frequentemente vistos por nós não sejam oriundos da medula óssea, mas de focos extra-medulares de proliferação eritroide, principalmente vistos nos baço, linfonodo e fígado. Essa hipótese está baseada no fato de que é reconhecido que esses mesmos focos de hematopoese extramedular são responsáveis pela liberação dos precursores eritroides nucleados menos imaturos (metarrubrícitos e rubrícitos) vistos na circulação. Dessa forma, se é possível que essas células sejam oriundas desses sítios, talvez os policromatófilos também sejam. Entretanto, o motivo pelo qual a policromasia foi vista frequentemente nos casos aqui descritos e não em outros permanece sem explicação.

As alterações referentes a alguns leucogramas (aqueles com leucopenia por neutropenia) e a algumas contagens de plaquetas (aquelas com trombocitopenia) foram interpretadas como distúrbio mielotísico, pois gatos com LMA M6, assim como com outros neoplasmas medulares, desenvolvem essas alterações em virtude da proliferação celular desordenada na medula óssea, o que acaba por ocupar os espaços virtuais dos outros componentes celulares (Valli 2007a,b). Diferentemente de outros tipos de leucemia, a anemia vista na LMA M6 não é mielotísica, pois o compartimento eritroide faz parte do clone maligno, e, portanto, há um aumento dos precursores eritroides. Nesses casos, o que ocorre é uma interrupção na maturação eritroide, caracterizada por uma dissociação entre os compartimentos de multiplicação e maturação (Valli 2007a, Fighera \& Graça 2010), exatamente o que foi visto em todos os casos aqui descritos.

Um ponto interessante dos achados anatomopatológicos foi a ocorrência de proliferações de células hematopoéticas, principalmente da linhagem eritroide, mas também megacariocítica, fora da medula óssea. Em todos os casos, a quantidade 
de blastos, semelhantes aos vistos na medula óssea, era pequena, e a relação desses blastos para com os precursores menos imaturos era muito diferente da observada na medula óssea dos mesmos casos. Segundo alguns autores, é comum ocorrerem focos de hematopoese extramedular em casos de LMA M6 (Comazzi et al. 2000), principalmente eritroide e megacariocítica. Já outros autores reforçam a ideia de metastatização e afirmam que metástases hepáticas ocorrem em 30\%$40 \%$ dos casos (Valli 2007a). Até que ponto esses focos devem ser considerados como hematopoese extramedular ou metástase é discutível, pois as células vistas ali são diferentes das encontradas no neoplasma primário, confinado a medula óssea, mas, em pelo menos dois casos, a quantidade dessas células no fígado e rim causava distorções macroscópicas dos órgãos. Dessa forma, devemos nos ater muito mais ao fato de que embora possa ser compensatória à anemia, tal proliferação não traz benefícios, pelo contrário, vagarosamente oblitera e substitui o órgão afetado. Nesse ponto, é importante re-lembrar um conceito básico, descrito no clássico livro de histologia do Dr. Arthur Ham (Ham \& Cormack 1983) a partir da pergunta: "Por que o tecido mieloide e, consequentemente, a formação das células sanguíneas da série mieloide fica restrita, no adulto, às cavidades ósseas?" A principal teoria que explica o porquê das células hematopoéticas serem produzidas no interior dos ossos baseia-se principalmente no aspecto físico. Aqueles que defendem essa tese acreditam que se a hematopoese ocorresse fora das cavidades ósseas, o tecido hematopoético proliferaria até substituir por completo um determinado órgão. Esse tipo de problema não ocorre com a cavidade óssea, pois, por não ser possível a expansão, células produzidas se acomodam de maneira limitada. As células em excesso, que acabam sempre sendo as mais maduras e, consequentemente, as localizadas ao redor dos sinusoides, utilizam os vasos sanguíneos como um escoadouro. Mais recentemente, alguns pesquisadores determinaram que hepatócitos têm a capacidade de inibir a hematopoese in vitro. Esse achado corrobora a opinião de que as células parenquimatosas de órgãos que não a medula óssea produzem substâncias que antagonizam a hematopoese, talvez como uma forma de defesa contra o que foi anteriormente explicado.

Segundo alguns autores (Valli 2007a), os linfonodos de gatos com LMA M6 têm tamanho normal e dificilmente estão envolvidos com colonização neoplásica. Entretanto, nos casos aqui descritos, a linfadenomegalia foi um achado importante, tanto clínico $(3 / 10$ [30\%]) como de necropsia (3/7 $[42,8 \%])$. Além disso, em todos os casos em que estavam aumentados, esses linfonodos eram vermelhos, um padrão de apresentação bastante peculiar. Na histologia, focos de proliferação eritroide e megacariocítica eram vistos com frequencia (5/7 [71,4\%]) e, pelo menos nos três casos em que os linfonodos eram macroscopicamente vermelhos, substituíam quase totalmente parênquima nodal.

Um resultado marcante e visto em todos os casos aqui descritos foi a hemossiderose. Essa hemossiderose foi associada à incapacidade da medula óssea em realizar a eritropoese eficaz, dada a falha na maturação eritroide em decorrência do excesso de células do compartimento de multiplicação (blastos). Essa eritropoese ineficaz não utiliza o ferro disponível para formação da hemoglobina e consequentemente causa sobrecarga do mineral. Tal sobrecarga, confirmada pela visualização histológica do pigmento e por sua reação histoquímica com o Azul da Prússia era tão grave que em três dos sete casos $(42,9 \%$ dos casos) modificou macroscopicamente a cor do fígado, de vermelho-escuro para marrom-bronzeado. Em pelo menos um dos casos em que havia hemossiderose, ocorreu também marcada fibrose e proliferação de ductos biliares. Embora acúmulos acentuados de ferro no fígado possam culminar em lesão hepática crônica que evolui até cirrose em um típico quadro de hemocromatose, não é possível saber se a hemossiderose e a cirrose vistas nesse mesmo caso são achados independentes ou relacionados.

Outro resultado interessante ocorreu em um dos gatos afetados. Esse indivíduo apresentou achados hematológicos típicos de LMA M6B e teve sua medula avaliada citologicamente. O mielograma e os aspectos morfológicos da medula óssea desse caso em nada eram diferentes dos outros nove gatos. Entretanto, cerca de dois meses após o diagnóstico, o quadro hematológico mudou, e a medula óssea demonstrou achados quantitativos e qualitativos que permitiram o diagnóstico de LMA M4. Esse tipo de modificação fenotípica é bem conhecido em leucemias de humanos e sua ocorrência já foi descrita em gatos (Schalm 1975b, Engelman et al. 1986). Interessantemente é que por muitos anos, o distúrbio hematológico que atualmente denominamos de LMA M6B foi considerado como préleucêmico, ou seja, uma forma de apresentação de mielodisplasia que com frequência evoluía até o que atualmente denominamos de LMA M6A. Além disso, alguns desses casos continuavam a evoluir, em um continuum patologicum até outras formas de LMA. Assim, é possível que essa modificação fenotípica testemunhada por nós seja semelhante ao que foi no passado descrito em hematologia humana pela expressão "infidelidade de linhagem". Outra possibilidade, levantada há alguns anos, é que LMA M6 seja na verdade uma panmielopatia resultante de distúrbio de células-tronco mieloide e, à semelhança do que ocorre na síndrome de Di Guglielmo de humanos, ocasionalmente demonstre variações fenotípicas em sua apresentação (Facklam \& Kociba 1986).

\section{CONCLUSÕES}

Os resultados aqui apresentados demonstram a ocorrência esporádica de casos de LMA M6 em gatos na nossa região (10 casos em 10 anos de rotina). Assim, os clínicos de pequenos animais e os patologistas veterinários devem ater-se a esse fato, principalmente quando frente a históricos de anemia associada à anorexia ou inapetência e que culmina em emagrecimento progressivo em gatos adultos jovens (1-3 anos de idade) ou idosos (10 anos de idade ou mais). Hematologicamente, esse diagnóstico deverá ser aventado toda a vez em que ocorrer anemia macrocítica normocrômica ou macrocítica hipocrômica com marcada normoblastemia com ou sem policromasia. À semelhança do que fizeram outros autores acerca do tema policromasia na LMA M6 (Harvey et al. 1978), gostaríamos de ressaltar que mesmo que haja policromasia, na presença de outros critérios, o diagnóstico de LMA M6 jamais deve ser descartado. Embora os achados hematológicos aqui apresentados possam ser semelhantes àqueles vistos em anemias hemolíticas, clinicamente não há icterícia na LMA M6 e esse é um ponto fundamental no diagnóstico diferencial. 
É importante ressaltar que a ausência de dados referentes à situação do FeLV em nossa região impossibilita saber qual a influência desse agente nos casos de LMA M6, assim ressaltamos a importância de um inquérito epidemiológico que demonstre o status da população felina quanto a infecção pelo FeLV, bem como a necessidade da implementação de técnicas de diagnóstico virológico que permitam relacionar essa e outras doenças possivelmente causadas pelo FeLV com a infecção por esse vírus.

Agradecimentos.- A todos os colegas, clínicos de pequenos animais, que nos repassaram valiosas informações clínicas e hematológicas dos casos aqui descritos e frequentemente nos permitiram reavaliar hematologicamente seus pacientes, mas principalmente aos doutores Cesar Schmidt, Vagner Schmidt, Anelise Réquia, Alexandre Mazzanti, Lucia Maria Silveira e Marco Montoya.

\section{REFERÊNCIAS}

Anderson A.C. \& Johnson R.N.M. 1962. Erythroblastic malignancy in a beagle. J. Am. Vet. Med. Assoc. 141:944-946.

Bain B.J. 1998. Classification of acute leukaemia: The need to incorporate cytogenetic and molecular genetic information. J. Clin. Pathol 51:420-423.

Bain B.J. 2003. Diagnóstico em leucemias. 2ª ed. Revinter, Rio de Janeiro.

Bennetti J.M., Catovsky D., Daniel M.T., Flandrin G., Galton D.A., Gralnick H.R. \& Sultan C. 1976. Proposal for the classification of the acute leukaemias. French-American-British (FAB) Co-operative Group. Brit. J. Haematol. 33:451-458.

Bird C. \& Huggins C. 1971. Leukemia evoked with 7, 8, 12-trymethilbenz(a) anthracene in rat. I. Changes in spleen and thymus. J. Exp. Med. 134:12851297.

Comazzi S., Paltrinieri S., Caniatti M. \& De Dominici S. 2000. Erythremic mielosis (AML6er) in a cat. J. Feline Med. Surg. 2:213-215.

Couto C.G. 1992. Moléstias dos linfonodos e baço, p.2328-2348. In: Ettinger S.J. (Ed.), Tratado de Medicina Interna Veterinária: moléstias do cão e do gato. Vol.4. $3^{\mathrm{a}}$ ed. Manole, São Paulo.

Engelman R.W., Tyler R.D., Mosier D.A., Good R.A. \& Day N.K. 1986. Changing manifestations of a chronic feline haematopoietic proliferative disease during immunotherapy with staphylococcal protein A. J. Comp. Pathol. 96:177-204.

Facklam N.R. \& Kociba G.J. 1986. Cytochemical characterization of feline leukemic cells. Vet. Pathol. 23:155-161.

Falconer G.J., Irving A.C., Watson P.R. \& Ludwig J. 1980. A case of erythremic myelosis in a cat. N. Z. Vet. J. 28:83-84.

Fighera R.A. \& Graça D.L. 2010. Sistema hematopoético, p.337-422. In: Santos R.L. \& Alessi A.C. (Eds), Patologia Veterinária. Roca, São Paulo.

Groulade P. \& Guillon J.C. 1967. Erythremic syndrome in carnivore (Apropos of 2 cases in the rat and dog). Nouv. Rev. Fr. Hematol. 7:137-142.

Ham A.W. \& Cormack D.H. 1983. Os tecidos hematopoiéticos: o tecido mielóide, p.279-304. In: Ibid. (Eds), Histologia. 8ª ed. Guanabara-Koogan, Rio de Janeiro.

Harris N.L., Jaffe E.S., Diebold J., Flandrin G, Muller-Hermelink H.K., Vardiman J.W., Lister T.A. \& Bloomfield C.D. 2000. The World Health Organization classification of neoplastic diseases of the haematopoietic and lymphoid tissues: Report of the Clinical Advisory Committee Meeting, Airlie House, Virginia, November 1997. Histopathology 36:69-86.

Harvey J., Shields R.P. \& Gaskin J.M. 1978. Feline myeloproliferative disease. Changing manifestation in the peripheral blood. Vet. Pathol. 15:437-448.

Hurvitz A.I. 1970. Fine structure of cells from a cat with myeloproliferative disorders. Am. J. Vet. Res. 31:447-453.

Jacobs R.M., Messick J.B. \& Valli V.E. 2002. Tumors of the hemolymphatic system, p.119-198. In: Meuten D.J. (Ed.), Tumors in Domestic Animals. $4^{\text {th }}$ ed. Iowa State Press, Ames.

Jaffe E.S., Harris N.L., Stein H. \& Vardiman J.W. 2001. Pathology and Genetics of Tumors of Haematopoietic and Lymphoid Tissues. International Agency for Research on Cancer, Lyon.

Jain N.C. 1986. The leukemia complex, p.838-908. In: Ibid. (Ed.), Schalm's Veterinary Hematology. $4^{\text {th }}$ ed. Lea and Febiger, Philadelphia.
Jain N.C. 1993. The leukemias, p.319-348. In: Ibid. (Ed.), Essentials of veterinary hematology. Lea \& Febiger, Philadelphia.

Jain N.C., Kociba G.J., Thrall M.A., Blue J.T., Krehbiel J.D., Zinkl J.G., Grindem C.B., Latimer K.S., Harvey J.W. \& Raskin R.E. 1991. Proposed criteria for classification of acute myeloid leukemia in dogs and cats. Vet. Clin. Pathol. 20:63-82.

Jarrett W.F.H. \& Mackey L.J. 1974. Neoplastic diseases of the haematopoietic and lymphoid tissues. Bull. World Health Organ., Genève, 50:21-34.

Kawakami T.G., Theilen G.H., Dungworth D.L., Munn R.J. \& Beali S.G. 1967. "C"-type viral particles in plasma of cats with feline leukemia. Science 158:1049-1050.

Liu S.K. \& Carb A.V. 1968. Erythroblastic leukemia in a dog. J. Am. Vet. Med. Assoc. 152:1511-1516.

Maede Y. \& Murata H. 1980. Erythroleukemia in a cat with special reference to the fine structure of primitive cells in its peripheral blood. Japn. J. Vet. Sci. 42:531-541.

Maede Y., Murata H. \& Yamai H. 1979. Feline erythroleukemia: A case report. Jikken Dobotsu Experimental Animals 28:592-596.

McClure H.M., Keeling M.E., Custer R.P., Marshak R.R., Abt D.A. \& Ferrer J.F. 1974. Erythroleukemia in two infant chimpanzees fed milk from cows naturally infected with the bovine C-type virus. Cancer Res. 34:2745-2757.

MIC Cooperative Study Group. 1988. Morphology, immunologic and cytogenetic (MIC) working classification of the acute myeloid leukaemias. Second MIC Cooperative Study Group. Brit. J. Haematol. 68:487-494.

Moreau-Gachelin F. 2006. Lessons from models of murine erythroleukemia to acute myeloid leukemia (AML): Proof-of-principle of co-operativity in AML. Haematology 91:1644-1652

Morrison J.A. 2001. Erythremic myelosis. Compend. 23:880-886.

Moulton J.E. \& Harvey J.W. 1990. Tumors of the lymphoid and hematopoietic tissues, p.39-58. In: Moulton J.E. (Ed.), Tumors in Domestic Animals. $3^{\text {th }}$ ed. University of California, Los Angeles.

Ney P.A. \& D'Andrea A.D. 2000. Friend erythroleukemia revisited. Blood 96:3675-3680.

Oshiro L.S., Riggs J.L., Taylor D.O.N., Lennette E.H. \& Huebner R.J. 1971. Ferritin-label antibody studies of feline C-type particles. Cancer Res. 31:1100-1110.

Saar C. 1968. Erythremia and erythroleukemia in cats: Report on one case of each. Berl. Münch. Tierärztl. Wochenschr. 81:423-426.

Schalm O.W. 1972. Interpretation in feline bone marrow cytology. J. Am. Vet. Med. Assoc. 161:1418-1425.

Schalm O.W. 1975a. Myeloproliferative disorders in the cat: Erythremic myelosis. Feline Pract. 5:20-23.

Schalm O.W. 1975b. Myeloproliferative disorders in the cat: Progression from erythroleukemia into granulocytic leukemia. Feline Pract. 6:31-33.

Shimada T., Matsumoto Y., Okuda M., Momoi Y., Bonkobara M., Watari T., Goitsuka R., Ono K., Goto N. \& Tsujimoto H. 1995. Erythroleukemia in two cats naturally infected with feline leukemia virus in the same household. J. Vet. Med. Sci. 57:199-204.

Tolle D.V., Fritz T.E. \& Norris W.P. 1977. Radiation-induced erythroleukemia in the beagle dog: A hematologic summary of five cases. Am. J. Pathol. 87:499-510

Valli V.E., Jacobs R.M., Parodi A.L., Vernau W. \& Moore P.F. 2002. Histological classification of hematopoietic tumors of domestic animals. $2^{\text {nd }}$ ed. WHO/ AFIP, Washington.

Valli V.E.O. 2007a. Acute myeloid leukemias, p.367-424. In: Ibid. (Ed.), Veterinary Comparative Hematopathology. Blackwell, Ames, Iowa.

Valli V.E.O. 2007b. Hematopoietic system, p.107-324. In: Maxie M.G. (Ed.), Jubb, Kennedy, and Palmer's Pathology of Domestic Animals. Vol.3. $5^{\text {th }}$ ed. Saunders Elsevier, Philadelphia.

Ward J.M., Sodikoff C.H. \& Schalm O.W. 1969. Myeloproliferative disease and abnormal erythrogenesis in the cat. J. Am. Vet. Med. Assoc. 155:879-888.

Watanabe Y., Sekine T., Yabe M. \& Kadota K. 1998. Myeloproliferative disease in a calf. J. Comp. Pathol. 119:83-87.

Watson A.D., Huxtable C.R. \& Hoskins L.P. 1974. Erythremic myelosis in two cats. Aust. Vet. J. 50:29-33.

Zawidzka Z.Z., Janzen E. \& Grice H.C. 1964. Erythremic myelosis in a cat: A case resembling Di Guglielmo's syndrome in man. Pathol. Vet. 1:530-541. 